\section{Commentary: Regionalization of surgery for type A aortic dissection: What does this really mean?}

\author{
Alan M. Speir, MD
}

The Socratic Method is ascribed to an Athenian Greek who died in 399 BC. Socrates is credited among the founders of Western philosophy, and his method of teaching is still utilized today, particularly in legal education. The method employs a technique whereby an inquisitor presents a series of questions and an interlocutor attempts to answer the questions, revising the central hypothesis as indicated. ${ }^{1}$ This seems to be the method of reasoning applied by the authors of a recent Expert Opinion. ${ }^{2}$ Despite asking many appropriate, organized, and well-referenced questions, the fundamental question posed remains incompletely answered.

In their section "The Nature of the Beast," the authors address what becomes the primary conundrum of the article: Given the $1 \%$ to $2 \%$ mortality per hour after acute type A aortic dissection (ATAAD), ${ }^{3}$ are patients better served by undergoing surgery as expeditiously as possible even if the procedure is performed in a center that rarely performs these procedures (low volume), or should patients be transferred to centers with more expertise where such procedures are performed more frequently (high volume)? To address this central issue, data are presented that have been derived from several focused registries, including the International Registry of Acute Aortic Dissection, the Nationwide Inpatient Sample of North America, the National Institute for Cardiovascular Outcomes Research, the National Adult Cardiac Surgery Audit registry from the United Kingdom, and the German Registry for Acute Aortic Dissection Type A, as well as other specific references concerning the surgical volume-clinical outcome relationship.

\footnotetext{
From the Department of Cardiac Surgery, Inova Heart and Vascular Institute, Falls Church, Va.

Disclosures: The author reported no conflicts of interest.

The Journal policy requires editors and reviewers to disclose conflicts of interest and to decline handling or reviewing manuscripts for which they may have a conflict of interest. The editors and reviewers of this article have no conflicts of interest.

Received for publication July 11, 2020; revisions received July 11, 2020; accepted for publication July 15, 2020; available ahead of print July 19, 2020.

Address for reprints: Alan M. Speir, MD, Department of Cardiac Surgery, Inova Heart and Vascular Institute, 3300 Gallows Rd, Falls Church, VA 22042 (E-mail: alan. speir@inova.org).

J Thorac Cardiovasc Surg 2021;161:1738-9

0022-5223/ $\$ 36.00$

Copyright $₫ 2020$ Published by Elsevier Inc. on behalf of The American Association for Thoracic Surgery

https://doi.org/10.1016/j.jtcvs.2020.07.055
}

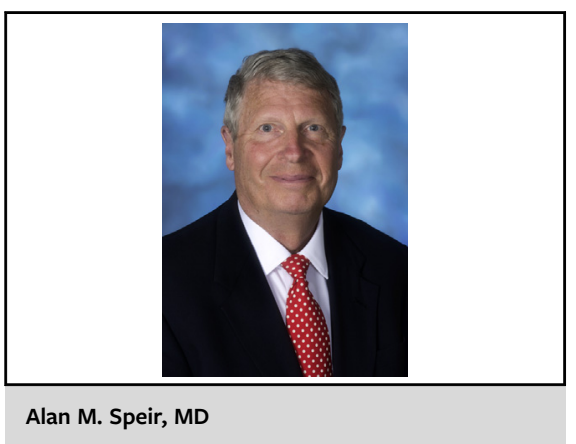

CENTRAL MESSAGE

Regionalization for surgery for

complex aortic dissection is

more complicated than trans-

ferring patients to a high-volume

aortic center.

Among the questions presented are the volume of cases that differentiates low-volume from high-volume institutions, as well as the perceived appropriate volumes for individual surgeons. They recommend, after reviewing a wide range of data, that a high-volume center would perform 7 repairs of ATAADs annually, and further suggest that it "seems reasonable to consider a high-volume ATAAD surgeon as performing at least 5 or more repairs per year"; that is, a repair of aortic dissection every 2.5 months. This annual volume has relevance as addressed in the section "How Much Does High Volume Matter?" Despite the supportive data from Chikwe and colleagues ${ }^{4}$ that "reported results from high-volume surgeons within the Nationwide Inpatient Sample of North America database and found that results were significantly better than that achieved by low-volume surgeons," review of the large international databases are not all consistent with this volume-outcome relationship and, in fact may confuse the issue because "the outcomes vary widely, even in high-volume aortic centers of excellence" 2 as well as the fact "that the improvements in outcomes have been seen not only in high-volume aortic centers of excellence but also in other centers."4-7

In the section "What are the Risks and Benefits of Transfer to a High-Volume Center?", the question concerns the fact that "a quarter of all Medicare beneficiaries present to a hospital without open heart surgery capabilities, whereas another $50 \%$ present to a low-volume hospital performing $<7$ ATAAD procedures per year." 8 Given the evidence from some, but not all of their references, the authors conclude that transfer to a high-volume facility with expertise in repair of ATAAD is appropriate from a clinical 
outcome perspective and this justifies the risks of prolonged transfer times and delayed surgical intervention. It is this premise that becomes synonymous with regionalization.

The authors have attempted to address a contentious and debated subject and have justified their conclusions by selected references and outcomes from the large international databases despite the limitations of such sources. What has been unfortunately omitted is clarification of the term regionalization. Is the transfer for care of a specific patient population to a surgical center with documented expertise, in fact what regionalization actually represents? Rather, isn't this perception of regionalization incomplete? Wouldn't regionalization also require closure of all institutions that perform fewer than an agreed upon minimum number of cases, as well as closure of centers with poor clinical outcomes regardless of volume, centralizing such care to high-volume centers with excellent documented outcomes? This represents a very real, but different, issue that is not addressed. Given the societal demands for transparency of institutional and surgeon results, it is this relevant question that will need to be addressed sooner rather than later.

\section{References}

1. Gross R. Socrates' Way. New York: Penguin Putman, Inc; 2002.

2. Gambardella I, Lau C, Girardi L. Has the time come for regionalization of surgery for acute type A dissection? J Thorac Cardiovasc Surg. 2021;161:1734-7.

3. Hagan PG, Nienaber CA, Isselbacher EM, Bruckman D, Karavite DJ, Russman PL, et al. The international registry of acute aortic dissection (IRAD): new insights into an old disease. JAMA. 2000;283:897-903.

4. Chikwe J, Cavallaro P, Itagaki S, Seigerman M, DiLuzzo G, Adams DH. National outcomes in acute aortic dissection: influence of surgeon and institutional volume on operative mortality. Ann Thorac Surg. 2013;95:1563-9.

5. Knipp BS, Depp GM, Prager RL, Williams CY, Upchurch GR, Patel HJ. A contemporary analysis of outcomes for operative repair of Type A aortic dissection in the United States. Surgery. 2007;142:524-8.

6. Bashir M, Harky A, Fok M, Shaw M, Hickey GL, Grant SW, et al. Acute type A aortic dissection in the United Kingdom: surgeon volume-outcome relation. $J$ Thorac Cardiovasc Surg. 2017;154:398-406.

7. Kruger T, Conzelmann LO, Bonser RS, Borger MA, Czerny M, Wildhirt S, et al Acute aortic dissection type A. Br J Surg. 2012;9:1331-44.

8. Goldstone AB, Chiu P, Baiocchi M, Lingala B, Lee J, Rigdon J, et al. Interfacility transfer of Medicare beneficiaries with acute type A aortic dissection and regionalization of care in the United States. Circulation. 2019;140:1239-50.

\section{See Article page 1734 .}

\section{Commentary: A situation where time is of the essence except when it is not}

\author{
Joseph S. Coselli, MD, and \\ Vicente Orozco-Sevilla, MD
}

Check for updates

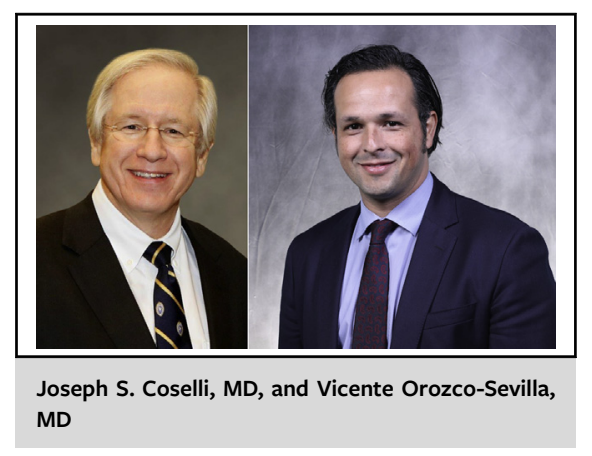

CENTRAL MESSAGE

In the treatment of ATAAD, the

risk of delay is balanced by

experienced hands.

Does the survival of a patient with an acute type A aortic dissection (ATAAD) depend on being in the right place at the right time? Approximately 60 years ago, a young physician experiencing incapacitating chest pain was most certainly in the right place at the right time, when, for the first time, surgeons were able to successfully repair an acute dissection of the aorta by resuspending the aortic valve and 